\title{
A New Perspective on Competency Management Implemented Through Effective Human-Computer Interaction
}

\author{
Elspeth McKay and Kathy Henschke \\ School of Business Information Technology, RMIT University, Australia
}

\begin{abstract}
Making an informed decision on whether an individual is suited to undertake an educational course or industry training programme can be very frustrating. When dealing with young adults at different cognitive skill levels, it is important to be able to identify and distinguish between their knowledge/competency levels, mostly on the basis of the evidence gathered from test-items. The current absence of appropriate measurement tools to determine skill/competency/knowledge levels remains a practical issue. The main aim of this paper is to discuss the management of this important differentiation in cognitive skill performance. One of the dilemmas surrounding this type of competency evaluation is the time it takes to test an individual. Insisting for instance, that a novice undergoes a long and arduous test, including many difficult testing items, results in lowered self-esteem, reduced motivation for learning something new, may induce stress related disorders. Similarly, expecting a more competent individual to undergo numerous simple test-items can generate the same negative result. A Competency Management System (CMS) is presented to initiate effective human-computer interaction (HCI) for cognitive skills assessment.
\end{abstract}

Keywords: Effective HCI, ICT, eLearning, instructional design, workplace training, experiential learning, knowledge navigation, competency management system

\section{BACKGROUND}

Today's large business entities need to employ a wide range of people with diverse skills across their organizational network. The development of high level skills across the workforce is expensive and requires major investment. The cost to employers of vocational education and structured training (even 10 years ago) has been estimated by the Australian National Training Authority in 1996 as $\$ 6.186$ billion, which reflects $57 \%$ of the total training cost of $\$ 10.845$ billion (Richardson 2004).

Traditionally, employers view training as an expensive solution that is implemented to fix problems. In the current climate of changing work practices, every time a new information and communications technology

Please use the following format when citing this chapter:

McKay, E. and Henschke, K., 2009, in IFIP International Federation for Information Processing, Volume 292; Evolution of Information Technology in Educational Management; Eds. Tatnall, A., Visscher, A., Finegan, A., O’Mahony, C., (Boston: Springer), pp. 95-106. 
(ICT) tool enters the work-environment employers seem to pour endless amounts of money into upgrading their employees' skill base (McKay, Axmann, Banjanin \& Howat, 2007). The difficulty of this continual investment in workplace learning begs the question of what we know about the impact of these emerging ICT tools on institutional effectiveness. Furthermore, a large number of the eLearning solutions that have been implemented recently have been poorly designed and inadequately tested. Much of the paper-based training materials are simply loaded into a learning management system or courseware shell (McKay et al. 2007); without including adequate knowledge navigation or consideration for the principles of instructional design. eLearning implementations frequently fail to check whether learning actually occurs (as demonstrated by increased proficiency of the participants). In cases where checks are made, most attempts fail to use valid measures of the changes in proficiency (Fahy 2004). Within the corporate sector, it is no wonder that current eLearning solutions are poorly regarded by management and often remain unused by employees (McKay et al. 2007); thereby making them ineffective and an expensive waste of limited resources. There are similarities within the education sector, where there is further concern for upgrading higher-education graduates' employability skills.

\section{EMPLOYABILITY SKILLS FOR PROFESSIONAL PRACTICE}

A recent report from the ICT Skills Foresighting Working Group highlighted an increasing demand for ICT professionals with a broader skill set that includes technical and non-technical skills (DCITA, 2006). Yet a report funded by the Department of Education, Training and Youth Affairs (DETYA), notes the predicament of "... a large proportion of applicants for positions are considered unsuitable" (DETYA, 2000:vii). They identify key skill deficiencies of graduates in the areas of oral business communication; creativity and flair; problem solving; independent and critical thinking; and understanding of business practice.

Beckett \& Hager (2002) propose employability skills are acquired through completing a variety of tasks in a range of novel workplace contexts. However, providing the variety of classroom contexts for experiential learning/training is limited. So too are the scope of tasks that can be offered for execution. For example, there is an assumption that learning the theory of teamwork and then working on a team assignment within a university setting provides students with the teamwork skills that transfer into the workplace setting. Research evidence suggests that knowledge and skills gained in the classroom does not become usable at work without further learning in the workplace (Eraut 2002). Eraut explains why managing this type of skills' transfer is problematic by adding that 
acquired knowledge only has meaning once used; and its meaning is strongly influenced by previous contexts of use.

Professional competencies are developed through the experience of professional practice (Hager 2001 in Gonczi 2004). Over time professional practitioners develop expertise in their field of specialty. They acquire the ability to read situations on how to behave, how to communicate and act at work; and the capacity to make judgments. The Dreyfus Model of Skill Acquisition (DMSA) charts the incremental changes of a professional's cognitive skill development over five levels of proficiency: novice, advanced beginner, competent, proficient and expert. Benner (1982) and Smith \& Sadler-Smith (2006) found that learning needs of professionals varied according to their stage of professional development. Individuals in the early stages of professional development require more learning support in the form of guided instructions, feedback and affirmation; while learning approaches and materials required for the final stages of professional development should support holistic thinking and formation of abstract concepts to develop practice-based theory.

Learning/training practitioners responsible for planning the professional development of workplace personnel are required to recognise and accommodate the different stages of professional development. To manage this process, a clear knowledge of the differentiation of humans' information processing is vital. Competency management is now discussed using the DMSA as a means to appreciate the complexities of cognitive skill acquisition.

\section{UNDERSTANDING COGNITIVE SKILL ACQUISITION}

In any instructional/training event it is important to identify the learning domain (Clark et al. 1983), and to specify the tasks that are essential for developing the skills and knowledge to achieve the expected learning outcomes (the instructional goals). While DMSA shows incremental changes in cognitive skill acquisition, in this paper our use of the same term however divides cognitive skill development into two clear sets. As such, the first refers to the set of cognitive skills associated with declarative (knowing what); the second relates to the procedural knowledge (knowing how) (McKay \& Merrill 2003). This type of cognitive skill acquisition can be analysed in four discrete categories (van Dongen 1996):

1. Verbal information (knowing basic terms)

2. Intellectual skill development (basic rules, discriminating and understanding concepts and principles)

3. Intellectual skill (higher-order-rules, problem solving, the ability to apply concepts and principles in new situations)

4. Two different types of cognitive strategies (a) to identify sub-tasks, recognize un-stated assumptions, and (b) to recall simple prerequisite 
rules and concepts, integrating learning from different areas into a plan for solving a problem.

In some instances, these categories of skill can be embedded within the learning content (hierarchical skill development). However, this type of framework is unsuitable for some other training environments (building skills for a specific task). Instead, according to McKay (2007), the learning domain should concentrate on the intellectual skills associated with a particular problem solving issue (like deciding which form of public transport to catch to work).

\subsection{Identify Cognitive Style Preference}

It is not sufficient to categorize human information processing as neat DMSA skill categories (McKay, 2000). To fully understand the complexities of cognitive skill acquisition, one first needs to explore the various ways human-beings gather up their new information. The literature reveals research which distinguishes the human ability to process information, as a combination of mode of processing information, and the way people represent information during thinking (see Figure-1) (Riding \& Mathais 1991). There are two fundamental cognitive dimensions, 'Wholist-Analytic' and 'Verbal-Imagery' that affect human performance in two ways. The first relates to how information is perceived and interpreted, while the second relates to how already memorised related information is conceptualised (Riding 1993). Cognitive style is therefore understood to be an individual's preferred and habitual approach to organizing and representing information.

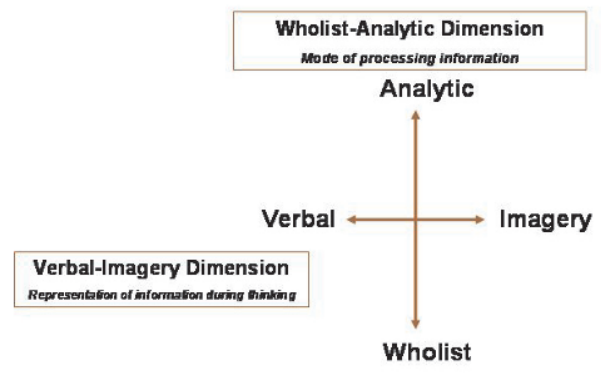

Figure-1: Cognitive style construct

Measurement of an individual's relative right/left hemisphere performance and cognitive style dominance has been a target of researchers from several disciplines over the last decade (Riding \& Rayner 1998). Different theorists make their own distinctions about cognitive differences (Riding \& Cheema 1991). According to Riding and Cheema, for example, the WholistAnalytic continuum maps to the cognitive categories used by other 
researchers (see Table 1). These well known terms are used frequently throughout the literature in a number of different research disciplines.

Table-1: Researchers' terms for processing information - mapped to Riding's WA continuum

\begin{tabular}{|c|c|}
\hline Terms describing cognitive differences & Researchers \\
\hline Levellers-sharpeners & (Holzman \& Klein 1954) \\
\hline Field dependence-field independence & (Witkin et al. 1962) \\
\hline Impulsive-reflective & (Kagan 1965) \\
\hline Divergers-convergers & (Guilford 1967) \\
\hline Holists-serialists & (Pask \& Scott 1972) \\
\hline Wholist-analytic & (Riding \& Cheema 1991) \\
\hline
\end{tabular}

The Wholist-Analytic dimension (or continuum) defines that learners tending towards the Wholist side of the continuum are able to understand a concept as a whole, but may find difficulty in disembedding its separate components (McKay 1999). On the other hand, learners who are identified towards the Analytic end of the scale, analyse material into parts, but find difficulty in understanding the whole concept.

The Verbal-Imagery continuum measures whether an individual is inclined to represent information verbally or in mental pictures during thinking (Riding \& Rayner 1998). Verbalisers prefer and perform best on verbal tasks, while Imagers are superior on concrete, descriptive and imaginal ones. When there is a mismatch between cognitive style and instructional material or mode of presentation, performance is deemed to be reduced (Riding \& Caine 1993).

The difficulty in the past for competency management has been in knowing how to initiate effective instructional strategies to suit a wide range of cognitive styles. An answer to this problem lies in knowing how to manage the interactivity of instructional format and cognitive style preferences. An effective tool is discussed next, which provides a means to operationalize cognitive style preference and instructional format has been used to initiate competency skill development (McKay, 2007).

\subsection{Meta-Knowledge Process Model}

Previous research has shown this variation in cognitive style, with participants demonstrating preference for verbal (textual) or visual (pictorial) representation (McKay 2007). For this reason, it is critical to create an instructional environment which caters for the full range of cognitive style preference with delivery options for users to choose from. To this end, the Meta-Knowledge Processing Model shown below represents an effective and robust learning systems' design tool (Figure-2). This Model articulates an adaptive courseware designing tool, which reflects the user's prefer ence for thinking mode (Verbal- Imagery), while also providing both 
Wholist-Analytic instructional strategies to capture the user's inherent information processing mode. Moreover this Model can also be used to broker the DMSA proficiency levels.

Drawing on the Meta-Knowledge Processing Model, every component of the learning/training environment can be described fully to provide detailed learning system specifications. This is especially important with the production of the visual resources. Each picture should be logged with the associated interactions for audio and access arrangements. To reduce (users') stress, it is also important to keep track of the inter-relating eResources. This ensures a seamless access path to the learning/training resources. Contemporary approaches to instructional design repeatedly lack an ability to recognise and accommodate the dynamics of cognitive processes necessary for online learning (see Figure-2). This systems' design modelling tool identifies interactive relationships between cognitive style and instructional format, and the need to adapt the instructional format dynamically. It requires a concurrent acquisition of meta-knowledge relating to the learner's cognitive performance with a knowledge-level-analysis of task difficulty (McKay 2000).

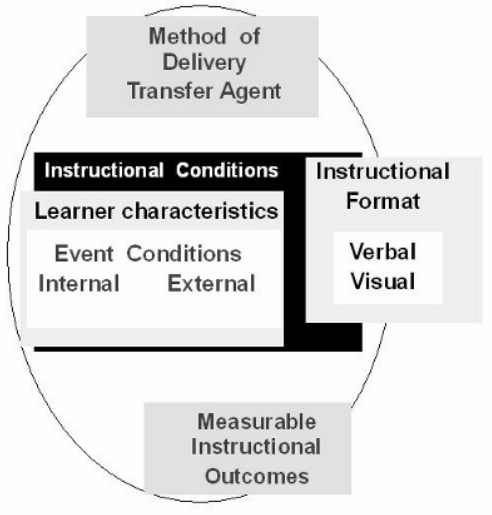

Figure-2: Meta-knowledge processing model

The instructional environment can be described in detail using this MetaKnowledge Processing Model to define each facet of the system. Consequently, the method of delivery that is to be chosen to achieve the measurable instructional outcomes, for instance: for each of the DMSA proficiency levels with graded expectations for novice, advanced beginner, competent, proficient and expert. This Model can also be used to determine readiness for study or skills development, when using computer keyboard is difficult. In cases such as this the delivery method (or transfer Agent as shown in Figure 2) could be identify replacing the keyboard with touch screen technology. This is where a systems designer may wish to keep track of specific learning system essentials: like ensuring that the learning systems are always fun to use, and the (knowledge) navigation is kept simple 
(Duchastel, 1991-2). For instance: instead of using a keyboard and mouse, users are to press the touch screen to navigate forward, backward and exit the learning programme.

To demonstrate how using a design tool such as the Meta-Knowledge Processing Model, can improve competency management through effective HCI a competency measurement pilot system is discussed next.

\section{COMPETENCY MANAGEMENT STRATEGIES}

The reasons why people need to develop new skills or retrain for the workplace are countless. In some cases the individual is merely committed to life-long-learning; while in others the choice to develop new skills may be due to unforseen circumstances: like responding to new management in an organizational change, or needing to find a different job because of an accident, or enduring long-term unemployment. Managing the decisions that are made concerning appropriate training/education/reskilling programmes for people after some type of traumatized event, it is important to differentiate what an individual knows, from what they do not. This paper describes a skills/competency measurement technique that is efficient, reliable, and safe to administer. Competency evaluation for both education and corporate training sectors is necessary to determine remedial intervention for youthful individuals, and adults requiring vocational re-training/ rehabilitation. Knowing an individuals cognitive style preference is critical (McKay 2000), because not all individuals respond to text and visual instructions in the same manner. Thereby incorporating features of the DMSA to determine skill level proficiency.

A new approach will therefore depend upon competency assessment that enables: differentiated teaching, provide adaptive cognitive skills measurement, correctly identify different levels of competency, promote selfconfidence and enhance motivation towards learning abilities. Benefits of such a competency management system (Anderson et al. 2007) increase opportunities for people to participate in appropriate learning/retraining programmes. In turn, this targeted reskilling enhances the socio-economic fabric of an economy by reducing wasteful welfare support, and promoting personal growth.

Motivation for a 'competency management system (CMS)' follows the successful Australian 2003 research project funded by the Telematics Trust: 'Automated Educational/Academic Skills Evaluation: Enhanced opportunities for young people returning to study or vocational training' (McKay 2007). The EASY project team developed a simple computerized cognitive skills testing instrument which showed clear differentiation of competency levels between participants. The Meta-Cognitive Process Model was used by the developer to customize the instructional conditions, which identified the users' attitude towards using a keyboard in a test-environment. A distinctive feature of the CMS is the innovative use of touch screen technology. 
Touch-screens offer a non-threatening mechanism to alleviate computerphobia (Fisher 1991). However, the EASY pilot had several instructional design issues which need to be improved. Firstly, the EASY test-items were grouped into subject categories, not in order of competency requirement. By using the pilot results, it was possible to reorder the test-items from simple to more difficult, adding more test-items at each competency level. This initiates the development of a reliable competency measurement tool to identify individual cognitive performance. This customized cognitive performance test instrument identified where appropriate intervention, based on existing cognitive skill level, and assisted an EASY user select appropriate entry level for courses/training programmes (McKay, Martin \& Izard 2005).

Once the competency hierarchy has been developed, an 'Adaptive Instructional Differentiation (AID)' measurement tool will be built to enhance the reliability of EASY. In simple terms, the AID competency measurement tool captures the user's response time and scoring (right/wrong) to logically modify the sequence of test-items. If a user has quickly and correctly answered 2 or 3 simple level test-items, then the EASY-AID will move transparently into the next skill/competency level. Conversely, if the user is having difficulty within a competency skill level, the test-items offered will remain within that level or even revert to the previous lower skill level. Once the user's skill/competency level has been determined, EASY-AID will acknowledge their participation and terminate the test. In addition, to respond to the popularity of the moving image expressed by the EASY Mk-2 users in the 2003 project (McKay 2007), video clips will be used to stimulate elevated attitudinal/motivational outcomes. The fundamentals of instructional design strongly suggest absolute necessity for "show-me" visual examples (Merrill 2003).

EASY-AID will be implemented within community welfare services, government agencies and places of learning (including the secondary school system); where differentiated teaching strategies are a necessity for dealing with the wide range of skills and competency levels of people wishing to take up retraining programmes and/or return to study.

\section{EASY-AID FEATURES}

The first enhancement will be the empirical reordering and expansion of the original screening test-items (identified in the 2003 Telematics Final Report); thereby filling in the gaps in cognitive performance, identified from the 2003 data analysis with newly designed test-items.

The next step will be to design, test and build adaptive assessment instrumentation using ICT tools, which determine an individual's success on individual cognitive skills' test-items, while monitoring the overall time an individual takes to complete the whole skills' test. The EASY-AID system will test for competency with: 
- Literacy skills - written, oral comprehension, expression

- Numeracy skills

- Problem solving and organization

- Memory and concentration levels

To satisfy the instructional conditions/learner characteristics identified in the Meta-Knowledge Processing Model, the electronic content for the EASY-AID system will involve everyday activities including: identification of familiar objects, decisions on magnitude (basic maths), health and safety, food preparation, and knowledge of consumer awareness issues. These lifeskills examples will be implemented through graphical metaphors involving objects that may include: pictures, textual paragraphs and diagrams, and video vignettes (including audio). The input device implemented for the EASY-AID system will be through touch screen devices (human tactile response/stylus-pen).

Success rate and completion times will be logged by EASY-AID, and as such will be transparent to the participant. Personal details of the EASYAID user will not be stored electronically by the system. These confidential data will be the responsibility of the facilitator.

\section{EASY-AID APPLICATION}

It is expected that EASY-AID will facilitate the following outcomes:

1. Enable differentiated teaching: Correctly targeted learning/training programmes that facilitate appropriate instructional/training strategies are prescribed on the basis of an appropriate skill diagnosis.

2. Provide adaptive cognitive skills measurement: Tailoring the competency skills' assessment session increases self-worth/confidence/ motivation through: (a) reducing the time to take a test, and by providing a more efficient measurement level of skill/competency/ knowledge levels, (b) giving credit for more rapid completion of task.

3. Correctly identify different levels of competency: A widely dispersed skills monitoring device that tracks progress is especially important for locating cognitive skill deficiencies following some kind of traumatized life-event.

4. Promote inclusive learning environments through assistive technology: When touch screen technologies are utilized as the sole input device, this increases accessibility to cognitive assessment for a wide range of physical disabilities, including the recovery from spinal cord injuries, stroke, or amputees, removing the need to interact with the EASY-AID system through a computer keyboard and mouse device (McKay, 2007). 


\section{CONCLUSIONS}

The development of professional practitioner skills is an on-going priority for organisations and educational institutions. The use of adaptive assessment instrumentation in computer-based training materials not only promotes learning by catering to individuals at different skills levels with different learning requirements; but also has the potential to track the progress of professional skills' development. Once the CMS is fully developed it will be trialled by students at the start and end of their 12month industry placement. This is an experiential workplace programme that occurs in the third year of their 4-year undergraduate Business Information Systems degree. Results of these trials will track the contribution of workplace learning in the development of the students' professional skills.

The findings will highlight complications that are amplified when assessing people who are entering vocational rehabilitation, looking for work after a long absence. The significance of this competency management technique is highlighted by the range of educational/training programmes that would benefit from such a tool. For instance, proactive skills/knowledge testing of young children can reveal where remedial instructional activities should best begin to correct a literacy problem. Differentiating competency in older people means there can be more effective decisions made for their re-entry to study or re-skilling for a new job.

\section{REFERENCES}

Anderson, N., Lankshear, C., Courtney, L. \& Timms, C. (2007). Girls and ICT survey: Initial findings, Curriculum Leadership Journal, Retrieved 29/02/07 from Http://Cmslive.Curriculum.Edu.Au/Leader/Default.Asp? $\mathrm{Id}=13812$

Beckett, D. \& Hager, P. (2002). Life, Work and Learning: Practice in postmodernity, London \& NY, Routledge.

Benner, P. (1982) From Novice to Expert. The American Journal of Nursing, 82, 402-407.

Clark, R. C., Elam, R. J. \& Merrill, M. D. (1983). Training Content Experts to Design Instruction: An Adaptation of Component Display Theory. Performance \& Instruction Journal. September: 10-15.

DCITA (2006). Building Australian ICT skills: Report of the ICT Skills Foresighting Working Group. In Australia, C. O. (Ed.) Barton, ACT.

DETYA (2000). Employer satisfaction with graduate skills: Research Report 99/7, Feb 2000 Evaluations and Investigations Program. In Division, H. E. (Ed.) Canberra.

Duchastel, P. (1991-1992). Towards methodologies for building knowledgebased instructional systems. Instructional Science 20(5-6): 349-358.

Eraut, M. (2002) The interaction between qualifications and work-based learning. in K. Evans, P. H., L. Unwin (Eds.) Work to Learn. London, Kogan Page. 
Fahy, J. F. (2004). Media Characteristics and Online Learning Technology. Theory and Practice of Online Learning. T. A. F. Elloumi (Ed.) Canada, Athabasca University. Available through http://cde.athabascau.ca/ online book/copyright.html ISBN: 0-919737-59-5

Fisher, M. (1991). Computerphobia in Adult Learners. Computer Education: 14-19.

Gonczi, A. (2004). The new professional and vocational education. In Foley, G. (Ed.) Dimensions of Adult Learning: Adult education and training in a global era. Crows Nest, NSW, Allen \& Unwin.

Guilford, J. (1967). The Nature of Human Intelligence. NY, McGraw-Hill.

Holzman, P. \& Klein, G. (1954). Cognitive-system principles of levelling and sharpening: Individual differences in visual time-error assimilation effects. Journal of Psychology 37: 105-122.

Kagan, J. (1965). Individual differences in the resolution of response uncertainty. Journal of Personality and Social Psychology 2: 154-160.

McKay, E. (1999). An investigation of text-based instructional materials enhanced with graphics. Educational Psychology 19(3): 323-335.

McKay, E. (2000). Instructional Strategies Integrating the Cognitive Style Construct: A Meta-Knowledge Processing Model (Contextual Components That Facilitate Spatial/Logical Task Performance): An Investigation of Instructional Strategies That Facilitate the Learning of Complex Abstract Programming Concepts through Visual Representation. Applied Science (Computing and Mathematics Department). Waurn Ponds, Geelong, Australia, Deakin University, Available online from http://tux.lib. deakin.edu.au/adt-VDU/public/adt-VDU20061011.122556/

McKay, E. (2007). Planning effective HCI to enhance access to educational applications, International Journal Universal Access in the Information Society. Springer Berlin / Heidelberg(6:1). ISSN:1615-5289(200706)6:1; 1:0. 77-85.

McKay, E., Axmann, M., Banjanin, N., \& Howat, A. (2007). Towards webmediated learning reinforcement: Rewards for online mentoring through effective human-computer interaction. Paper presented at the 6th IASTED International Conference on Web-Based Education. Held March 14-16, Chamonix, France, p:210-215, ISBN:978-0-88986-650-8, Retrieved 15/04/07 http://www.iasted.org/conferences/pastinfo-557.html.

McKay, E., Martin, J., \& Izard, J. (2005). Cognitive awareness in vocational training programmes: Targeting successful outcomes for young people and those wishing to undertake vocational training. Paper presented at the 3rd International Conference on Universal Access in Human-Computer Interaction, held at the 11th International Conference on HumanComputer Interaction (AC, UAHCI, HIMI, OCSC, VR, U\&I, EPCE):, Las Vegas.

McKay, E. \& Merrill, M. D. (2003), E. McKay (Ed.) Cognitive skill and Web-based educational systems. eLearning Conference on Design and Development: Instructional Design - Applying first principles of instruction. Informit Library: Australasian Publications On-Line: [Online] Available 25.1.07 (http://www.informit.com.au/library/) from http://search.informit. com.au/browsePublication;isbn=0864592841;res=E-LIBRARY. 96-108. 
Merrill, M. D. (2003), E. McKay, Ed. Keynote Address: Does your instruction rate 5 Stars? eLearning Conference on Design and Development: Instructional Design - Applying first principles of instruction, Melbourne, Informit Library: Australasian Publications OnLine: [Online] Available 25.1.07 (http://www.informit.com.au/library/) from http://search.informit.com.au/browsePublication; isbn=0864592841; res=E-LIBRARY 13-14.

Pask, G. \& Scott, B. C. E. (1972). Learning strategies and individual competence. International Journal Man-Machine Studies 4: 217-253.

Richardson, S. (2004). Employers' contribution to training, Formal Report: National Centre for Vocational Education Research (NCVER). ISBN 1 9208600 7. 2006.

Riding, R. (1993). A trainer's guide to learning design : Learning Methods Project Report. Birmingham, Assessment Research Unit, University of Birmingham, UK: 47.

Riding, R. \& Cheema, I. (1991). Cognitive styles - an overview and integration. Educational Psychology 11(3\&4): 193-215.

Riding, R. J. \& Caine, R. (1993). Cognitive style and GCSE performance in mathematics, English language and French. Educational Psychology 13(1): 59-67.

Riding, R. J. \& Mathais, D. (1991). Cognitive styles and preferred learning mode, reading attainment and cognitive ability in 11-year-old children. Educational Psychology 11(3 \& 4): 383-393.

Riding, R. J. \& Rayner, S. (1998). Cognitive Styles and Learning Strategies. UK, Fulton.

Smith, P. J. \& Sadler-Smith, E. (2006). Learning in Organizations: Complexities and diversities, London \& NY, Routledge.

van Dongen, C. (1996). Quality of life and self-esteem in working and nonworking persons with mental illness. Community Mental Health 32(6): 535-549.

Witkin, H. A., Dyke, R. B., Patterson, H. F., Goodman, D. R. \& Kemp, D. R. (1962). Psychological Differentiation. NY, Wiley. 